\title{
Transparent Conductive Films of Copper Nanofiber Network Fabricated by Electrospinning
}

\author{
Sungyeoul Kim, ${ }^{1}$ Hyundong Lee, ${ }^{1}$ Dahye Kim, ${ }^{2}$ DaAe Ko, ${ }^{1}$ Dojin Kim, ${ }^{1,2}$ \\ Hyojin Kim, ${ }^{1,2}$ and Soon-Gil Yoon ${ }^{1,2}$ \\ ${ }^{1}$ Graduate School of Advanced Circuit Substrate Engineering, Chungnam National University, Daejeon 305-764, Republic of Korea \\ ${ }^{2}$ Department of Materials Science and Engineering, Chungnam National University, Daejeon 305-764, Republic of Korea
}

Correspondence should be addressed to Dojin Kim; dojin@cnu.ac.kr

Received 31 July 2015; Accepted 4 October 2015

Academic Editor: Albert Nasibulin

Copyright (C) 2015 Sungyeoul Kim et al. This is an open access article distributed under the Creative Commons Attribution License, which permits unrestricted use, distribution, and reproduction in any medium, provided the original work is properly cited.

$\mathrm{Cu}$ nanofiber networks can be a good alternative of the Ag nanowire of high electrical conductivity while having the advantage of low price. An electrospinning method was developed to fabricate copper nanofiber network for use as a transparent conductive film on glass substrate. The effects of liquid diluents for electrospinning processability were examined in relation to the subsequent $\mathrm{Cu}$ nanofiber formation processes. Electrospinning solutions of copper acetate/polyvinyl alcohol (PVA) and copper nitrate trihydrate/polyvinyl butyral (PVB) were investigated. The polymer mixing solutions influenced the subsequent annealing temperatures for removal of the polymers and reduction of the formed $\mathrm{CuO}$ nanofibers to $\mathrm{Cu}$ metal nanofibers. The morphology and structures of the formed nanofiber networks were examined by scanning electron microscopy, energy dispersive spectroscopy, $\mathrm{X}$-ray diffraction, and so forth. The mixture with PVB provided lower annealing temperatures suitable for application to flexible substrates.

\section{Introduction}

Transparent conductive films (TCFs) are the key element of display panels adopted in many human interface devices. Indium-tin oxide (ITO) has been an excellent material used as the TCF for long time [1]. However, the portable electronics require flexibility as a general requirement in the electronics and the hard ITO showed degradation in electronic conductivity with bending $[2,3]$. Furthermore, the high price and limited supply of indium demanded a substitution material. A variety of techniques and materials to replace ITO have recently been studied including carbon nanotubes (CNTs), graphene, conducting polymers, metal nanowires, and their composites [4-17]. The web of nanowires of highconductivity materials are expected to show conservation of the electrical conductivity on bending substrates. In other words, the nanowire-to-nanowire contacts in motion were expected not to degrade the overall film conductivity. Actually, the web structural films revealed excellent reliability under bending of the substrates $[13,14]$. It was found that the performance (which was measured as the conductivity at a given transparency for a film) of silver films approached that of ITO while the CNTs showed lower conductivities [13, 14].

The vulnerability of silver, however, may be the relatively high price as a novel metal. As a consequence, they began to study copper as a candidate to replace ITO mainly because $\mathrm{Cu}$ is a relatively inexpensive material while showing similar conductivity. Several chemical methods were developed and commercialized for synthesis of $\mathrm{Cu}$ nanowires $[18,19]$. However, the length of nanowires was often limited to several micrometers and the conductivity of the films at a transparency was very poor because the uniform percolation of the nanowires was hardly established due to agglomeration [18]. Therefore, elaborate research is required to chemically fabricate long and thin nanowires. Furthermore, copper easily oxidized and the wire-to-wire contacts may reveal high contact resistances resulting in a low conductivity. As such, we studied electrospinning method to overcome the limitation of the method of spreading the $\mathrm{Cu}$ nanowires on substrates. Electrospinning (ES) is a process to obtain a fine 
thickness of long fibers of a variety of materials in large quantities at a low cost. Considering the complex chemical synthesis and purification process steps in the nanowire synthesis as well as the resulting insufficient length of the nanowires, the electrospinning can be a promising method to synthesize continuous $\mathrm{Cu}$ nanowires [20-23]. The figure-ofmerit similar to TCF of silver nanowires was demonstrated by electrospinning of $\mathrm{Cu}$ [23]. Furthermore, electrospinning is a method that can be easily modified to a large-area synthesis technique.

However, the source materials used for the electrospinning process need to be prepared with appropriate physical properties including the viscosity, which determines the diameter of the nanowires as well as the processability itself. For this purpose, the source chemicals are frequently mixed with viscous polymers that are to be removed later by heating. A typical example is polyvinyl alcohol (PVA) and it can be removed by heating to a rather low temperature below $200^{\circ} \mathrm{C}$ [24]. We investigated the electrospinning technique to fabricate films of copper nanofiber web having high conductivity for flexible substrate application. We also report the limitation of the technique for the purpose application.

\section{Experiments}

2.1. Electrospinning of $\mathrm{Cu}$ Acetate in PVA Solution. The PVA solution was made by mixing $5 \mathrm{~g}$ of polyvinyl alcohol (PVA, $\mathrm{Mw} ; 89,000-98,000)$ [25-27] in $50 \mathrm{~mL}$ of distilled water followed by stirring for 6 hours at $90^{\circ} \mathrm{C}$. Copper acetate $\left[\mathrm{CuCH}_{3} \mathrm{CO}_{2}\right]$ of $0.4 \mathrm{~mol}$ was added in a liter of the PVA solution with stirring for 6 hours at $60^{\circ} \mathrm{C}$. The prepared source was injected into a syringe to electrospin on the glass substrates of $3 \mathrm{~cm} \times 3 \mathrm{~cm}$ size to form a nanowire web of copper mixed in PVA. The distance of the syringe tip from the substrate was fixed at $10 \mathrm{~cm}$. The bias for electrospinning was fixed at $23 \mathrm{kV}$, and the electrospinning rate was $0.5 \mathrm{~mL} / \mathrm{h}$. The film thickness of the nanowire web was controlled by the amount of solution to be emitted from the syringe (from $0.01 \mathrm{~mL}$ to $0.04 \mathrm{~mL}$ ). Removing of PVA from the nanowire was done by heating up the substrates to $200-500^{\circ} \mathrm{C}$ for 2 hours in the atmosphere. It was found that only the heat treatment at $500^{\circ} \mathrm{C}$ completely removed PVA from the nanowires. This heat treatment in the air also oxidized the copper in the nanowires into copper oxide, and thus the copper oxide nanowires were then heat-treated at $200-500^{\circ} \mathrm{C}$ for 2 hours in a hydrogen atmosphere in order to reduce the copper oxide into copper. The complete reduction occurred only at $500^{\circ} \mathrm{C}$. The rather high heat treatment temperatures caused disconnection of $\mathrm{Cu}$ nanowires on the substrate. Furthermore, the temperature is too high to apply to the popular flexible substrates such as PEN (polyethylene naphthalate) and PET (polyethylene terephthalate) polymer films. The change of the nanowire chemistry was schematically depicted in Figure 1.

\subsection{Electrospinning of Cu Nitrate Trihydrate in PVB Solution.}

The polyvinyl butyral (PVB) solution was made by mixing $2.2 \mathrm{~g}$ of PVB $[28,29]$ in $20 \mathrm{~mL}$ of isopropanol/DI water $(8: 2)$ solution followed by stirring for 1 hour. Thereafter, $4.41 \mathrm{~g}$ of

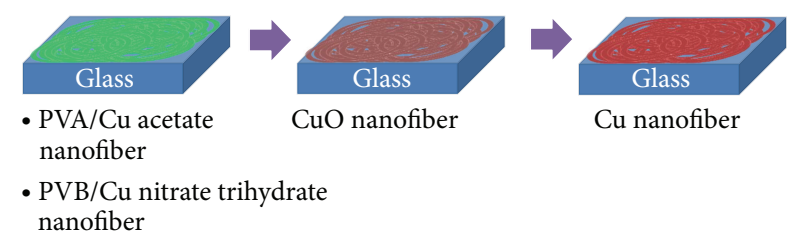

FIGURE 1: Schematic of the synthesis process for $\mathrm{Cu}$ nanofiber networks.

copper nitrate trihydrate $\left[\mathrm{Cu}\left(\mathrm{NO}_{3}\right)_{2} \cdot 3 \mathrm{H}_{2} \mathrm{O}\right]$ was mixed in the solution for 6 hours. Thus prepared source was injected into a syringe to electrospin on the glass substrates of $3 \mathrm{~cm} \times$ $3 \mathrm{~cm}$ size to form a nanowire web of copper mixed in PVB. The distance of the syringe tip from the substrate was again fixed at $10 \mathrm{~cm}$, but the bias for electrospinning was changed to an optimized value of $15 \mathrm{kV}$ at the electrospinning rate of $0.5 \mathrm{~mL} / \mathrm{h}$. The film thickness of the nanowire web was again controlled by the amount of solution to be emitted from the syringe (from $0.01 \mathrm{~mL}$ to $0.04 \mathrm{~mL}$ ). Removing of PVB from the nanowire was done by heating up the substrates to $200-$ $500^{\circ} \mathrm{C}$ for 2 hours in the atmosphere. It was found that the heat treatment at a lower temperature of $450^{\circ} \mathrm{C}$ could remove PVB from the nanowires. Furthermore, the reduction could be done at $300^{\circ} \mathrm{C}$ in this case, and this is the main advantage of using PVB as the mixing material for $\mathrm{Cu}$ source.

2.3. Characterization of the Films. The microstructures of the films were examined by the field-emission scanning electron microscope (FE-SEM, JSM-7000F, JEOL, Japan) equipped with energy dispersive X-ray spectroscopy (EDS) and the chemical composition and crystal structures by $\mathrm{X}$ ray diffraction (XRD, Rigaku, D/MAX-RC, Japan). Electrical resistance of the films was measured using a multimeter after formation of conductive pad of silver paste at both edges of the substrate. Light transmission was measured in the wavelength region of $400-700 \mathrm{~nm}$ using a UV-Visible spectrophotometer.

\section{Results and Discussion}

3.1. Cu Nanofiber Web by Electrospinning of Cu Acetate in PVA Solution. Figure 2 shows the surface morphologies of the electrospun nanofiber webs (a) for as-deposited nanofibers of copper acetate + PVA, (b) after oxidation of the nanofibers of (a) at $500^{\circ} \mathrm{C}$, and (c) after reduction treatment of (b) at $500^{\circ} \mathrm{C}$. The total amount of emission was $0.025 \mathrm{~mL}$ in this study unless otherwise specified. The electrospinning of the $\mathrm{Cu}$ acetate + PVA solution on the substrate formed smooth continuous fibers. The diameters of the electrospun nanofibers were distributed in the range of 50-150 nm (Figure 2(a)), and the distributed fibers are in amorphous form as indicated by the XRD measurement (Figure 3(c)).

The annealing of the electrospun fibers in air environment changed the physical chemistry of the fibers. In Figure 3(a), we compared the amount of carbon and oxygen atoms in the fibers as measured by the EDS with varying the heat treatment temperatures in the atmosphere. One observes 


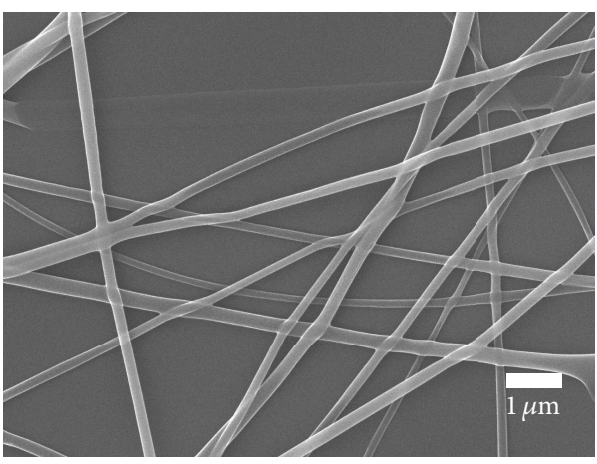

(a)

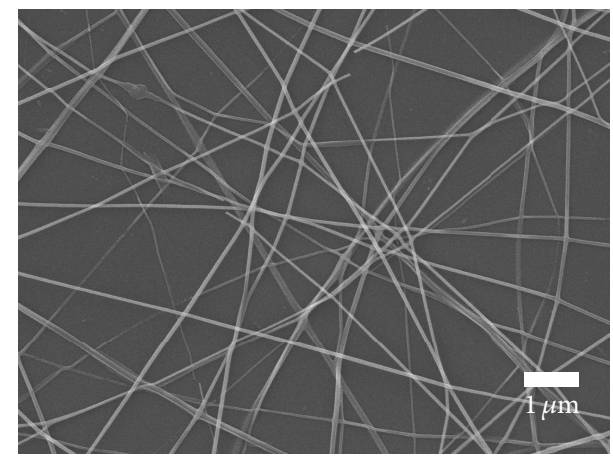

(b)

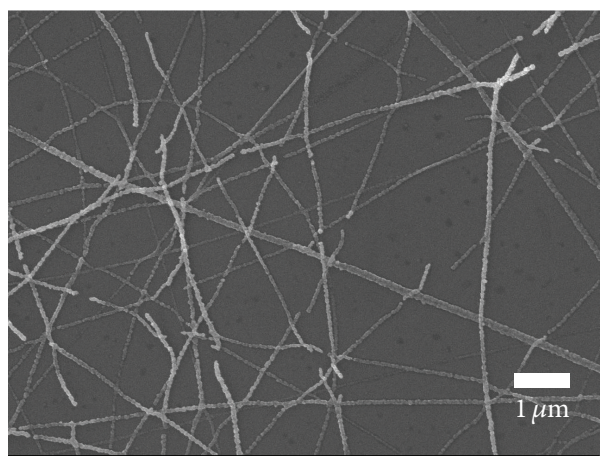

(c)

Figure 2: SEM images (a) of the $\mathrm{Cu}$ acetate/PVA nanofibers electrospun on glass substrate, (b) after annealing at $500^{\circ} \mathrm{C}$ in air for $2 \mathrm{~h}$ and (c) after subsequent annealing at $500^{\circ} \mathrm{C}$ in hydrogen atmosphere for $2 \mathrm{~h}$.

decreasing of $\mathrm{C}$ content and increasing of $\mathrm{O}$ content with increasing of the temperatures. The trend indicates that PVA degrades and evaporates with annealing in oxygen environment while $\mathrm{Cu}$ converts to $\mathrm{CuO}$. Figure 3(a) showed that the $\mathrm{C}$ content approaches zero at $500^{\circ} \mathrm{C}$, which indicates that the evaporation of PVA cannot be completed by an annealing below $500^{\circ} \mathrm{C}$. At the same time, the content of $\mathrm{O}$ also ever increased with the annealing temperature. This observation, or the removal of PVA going together with oxidation of $\mathrm{Cu}$, suggests that $\mathrm{Cu}$ is chemically connected with carbon of PVA. It was actually shown that the thermal decomposition temperature of PVA shifts to lower temperature when it is mixed with foreign entities, and the shift was explained by some defects induced in the polymer by the mixing $[30,31]$. However, the temperature for completion of the decomposition was not different at $450-500^{\circ} \mathrm{C}$. Actually, such a high temperature $\left(500-600^{\circ} \mathrm{C}\right)$ was required for calcination of electrospun copper acetate when mixed with polyvinyl alcohol or polyvinyl acetate solution [22, 23].

The results of EDS measurement in Figure 3(a) thus well coincide with the previous reports. The evaporation of PVA and decomposition of $\mathrm{Cu}$ acetate through the oxidation processing at $500^{\circ} \mathrm{C}$ led to a dramatic decrease in diameters as shown in Figure 2(b). The formed $\mathrm{Cu}$ oxide showed a stoichiometric $\mathrm{CuO}$ structure as clearly shown by the XRD pattern in Figure 3(c) [22]. The monoclinic $\mathrm{CuO}$ phase reveals (111) at $35.4^{\circ}$ and (200) at $38.5^{\circ}$ from JCPDS-5-0661.
The $\mathrm{CuO}$ nanofiber films formed through oxidation at $500^{\circ} \mathrm{C}$ were reduced at different temperatures in hydrogen ambient, and the EDS results are summarized in Figure 3(b). The reduction process could be completed via heat treatment at $500^{\circ} \mathrm{C}$ [as indicated by zero oxygen content (Figure 3(b))]. The diameter change after reduction was not remarkable, but agglomeration of $\mathrm{Cu}$ into particles on the glass substrate is remarkable. The observation indicates poor wetting between $\mathrm{Cu}$ and the glass substrate. The effect of reduction temperature on the $\mathrm{Cu}$ morphology was examined in more detail in Figure 4, which shows the morphologies after the reduction process at different temperatures, $300-600^{\circ} \mathrm{C}$, for 2 hours. The fibers maintained the continuity at $300^{\circ} \mathrm{C}$, where the reduction did not occur. The rather complete reduction occurred at $500^{\circ} \mathrm{C}$ as shown in Figure 3(b), but the liquefaction of $\mathrm{Cu}$ with agglomeration already began at $400^{\circ} \mathrm{C}$ and led to disconnection of the fibers as shown in Figure 4(b).

In conclusion, when PVA solution was electrospun, the requirement of high temperature $\left(500^{\circ} \mathrm{C}\right)$ for polymer decomposition also required high reduction temperature for $\mathrm{CuO}$. The latter resulted in melting and shrinking of $\mathrm{Cu}$ wires leading to breakage of percolation (or electrical connection) of the fibers. The net result is relatively high resistance of the $\mathrm{Cu}$ film as will be compared later in Table 1 .

3.2. Cu Nanofiber Web by Electrospinning of $\mathrm{Cu}$ Nitrate Trihydrate in PVB Solution. Cu nitrate trihydrate may oxidize 


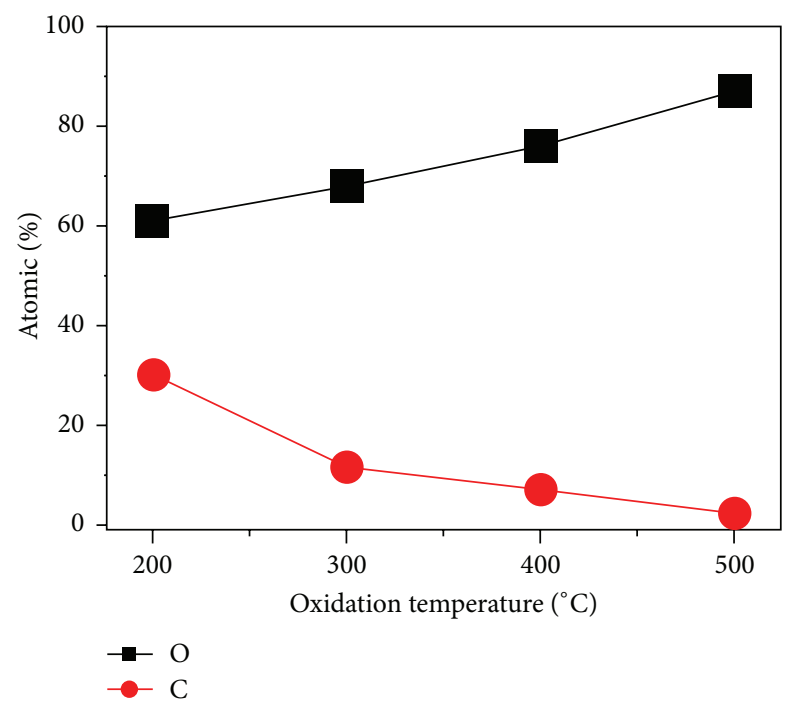

(a)

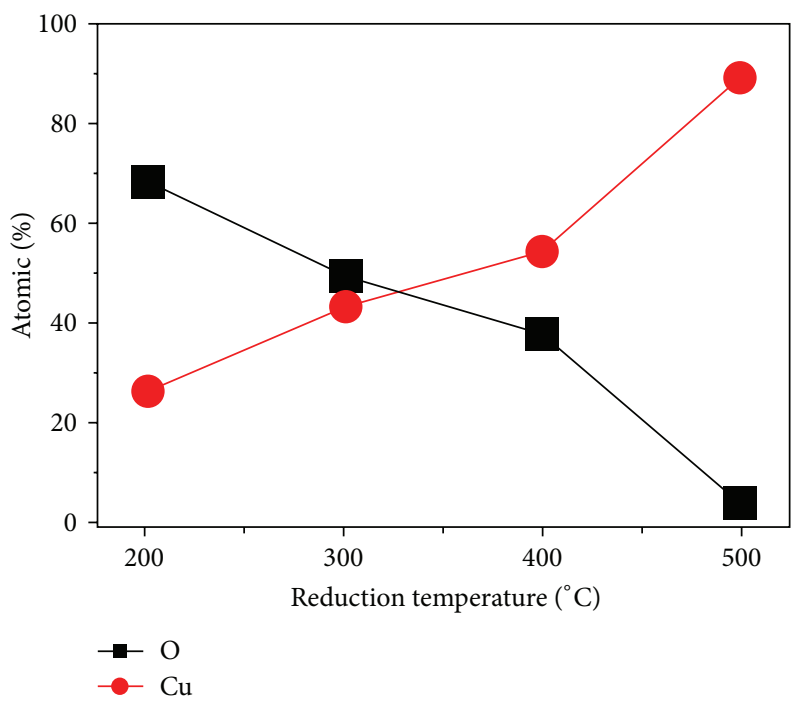

(b)

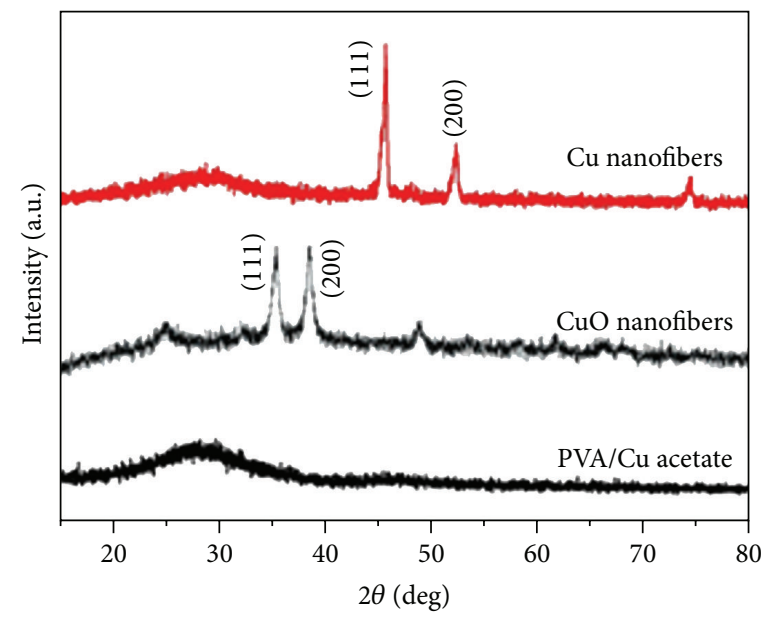

(c)

FIgURE 3: (a) Atomic percent of $\mathrm{C}$ and $\mathrm{O}$ measured by EDS after annealing at different temperatures in the air; (b) atomic percent of Cu and $\mathrm{O}$ measured by EDS after annealing at different temperatures in $\mathrm{H}_{2}$ environment. (c) XRD patterns for the as-electrospun nanofiber sample, after $500^{\circ} \mathrm{C}$ oxidation in (a) and after $500^{\circ} \mathrm{C}$ reduction in (b).

to $\mathrm{CuO}$ at temperatures below $\sim 200^{\circ} \mathrm{C}[32]$. The preliminary experiment showed that mixing in $\mathrm{PVB}$ revealed much thicker fibers of $>300 \mathrm{~nm}$. Figure 5(a) shows the morphology of the as-electrospun $\mathrm{Cu}$ nitrate trihydrate + PVB fibers, which clearly shows thicker diameters than the PVA mixture above. Again the total amount of the solution emitted from the nozzle was $0.025 \mathrm{~mL}$. Figure $5(\mathrm{~b})$ shows the morphology after oxidation treatment of Figure 5 (a) at $450^{\circ} \mathrm{C}$ for 2 hours and revealed that the diameters are in the range of 250$350 \mathrm{~nm}$. Figure 5(c) shows the morphology after subsequent reduction treatment at $300^{\circ} \mathrm{C}$ for 2 hours for the $\mathrm{CuO}$ nanofibers of Figure 5(b).

Actually the selected oxidation and reduction annealing temperatures in Figure 5 were obtained from the experimental results of Figure 6, which summarize the EDS measurements after the oxidation and reduction processes carried out at different temperatures. The results of Figure 6(a) clearly showed that carbon almost disappeared at $400^{\circ} \mathrm{C}$ as an indication of the complete removal of PVB from the fibers. It was shown that the pure PVB begins to decompose at $200^{\circ} \mathrm{C}$ and ends at $\sim 400^{\circ} \mathrm{C}$ [33-35]. While our observation well coincides with the literature observation, mixing with other materials could result in reduction of the decomposition temperature as observed with PVA [34]. Note also in Figure 6(a) that the $\mathrm{O}$ content monotonically increased with increasing temperatures. The steady trend may reflect a linear composition change of the copper oxide such as from $\mathrm{Cu}_{2} \mathrm{O}$ to $\mathrm{CuO}$. Therefore, the lower oxidation temperature of $450^{\circ} \mathrm{C}$ could lead to stoichiometry of $\mathrm{Cu}_{x} \mathrm{O}(1<x<$ 2 ) or defective copper oxide with poorer crystallinity. The significantly lower reduction temperature of $300^{\circ} \mathrm{C}$ shown in Figure 6(b) can be explained by the defective copper oxide formed at a lower temperature. The mechanism for such a low reduction temperature needs to be explored in more 


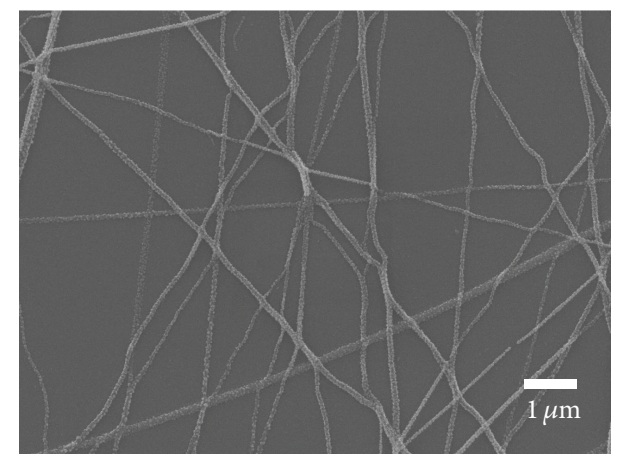

(a)

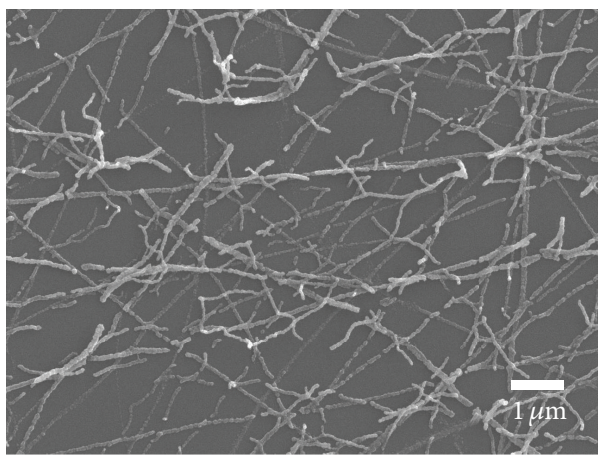

(c)

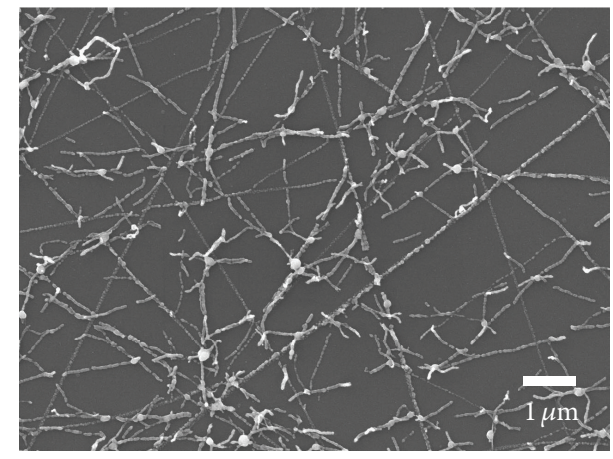

(b)

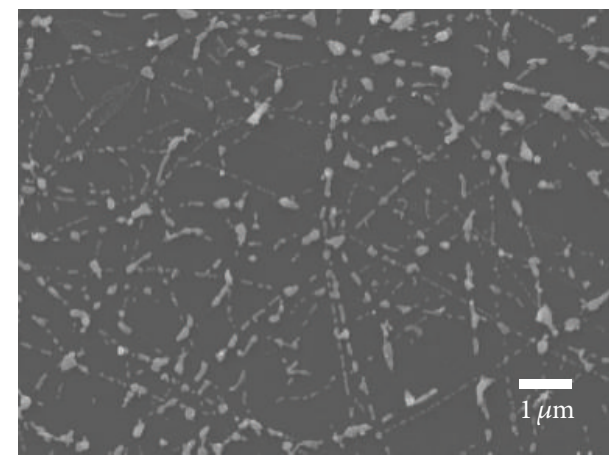

(d)

FIGURE 4: SEM image of $\mathrm{Cu}$ nanofibers formed via reduction of $\mathrm{CuO}$ nanofibers in hydrogen environment at different annealing temperatures of (a) $300^{\circ} \mathrm{C}$, (b) $400^{\circ} \mathrm{C}$, (c) $500^{\circ} \mathrm{C}$, and (d) $600^{\circ} \mathrm{C}$.

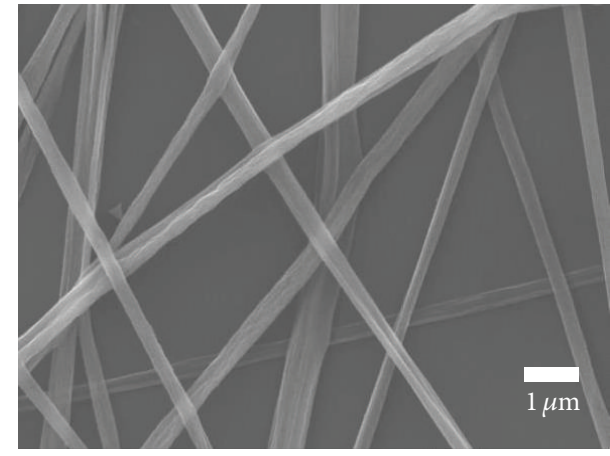

(a)

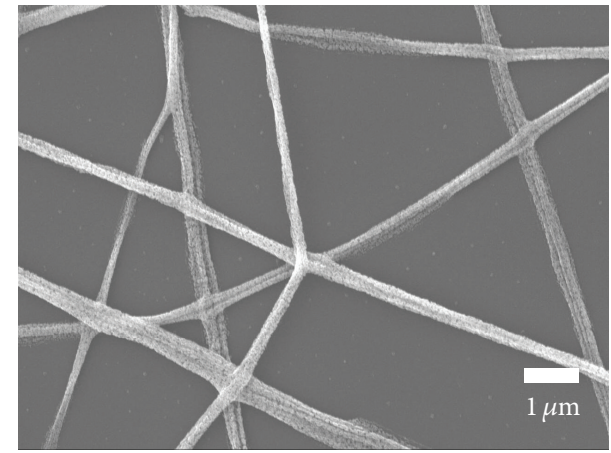

(b)

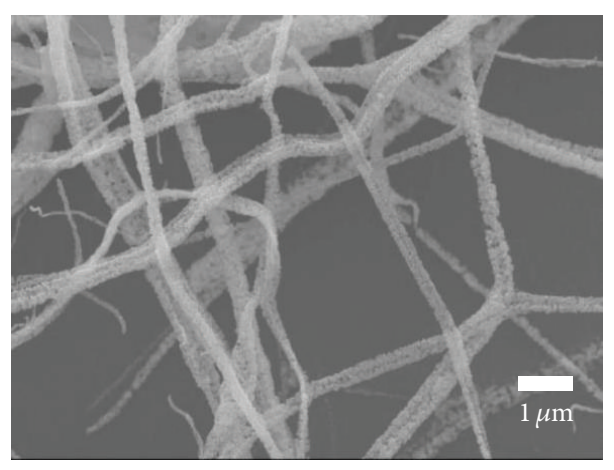

(c)

Figure 5: SEM images (a) of the electrospun Cu nitrate trihydrate/PVB composite fibers, (b) after oxidation annealing at $450^{\circ} \mathrm{C}$ in air ambient for $2 \mathrm{~h}$ and (c) after subsequent reduction annealing at $300^{\circ} \mathrm{C}$ in hydrogen atmosphere for $2 \mathrm{~h}$. 


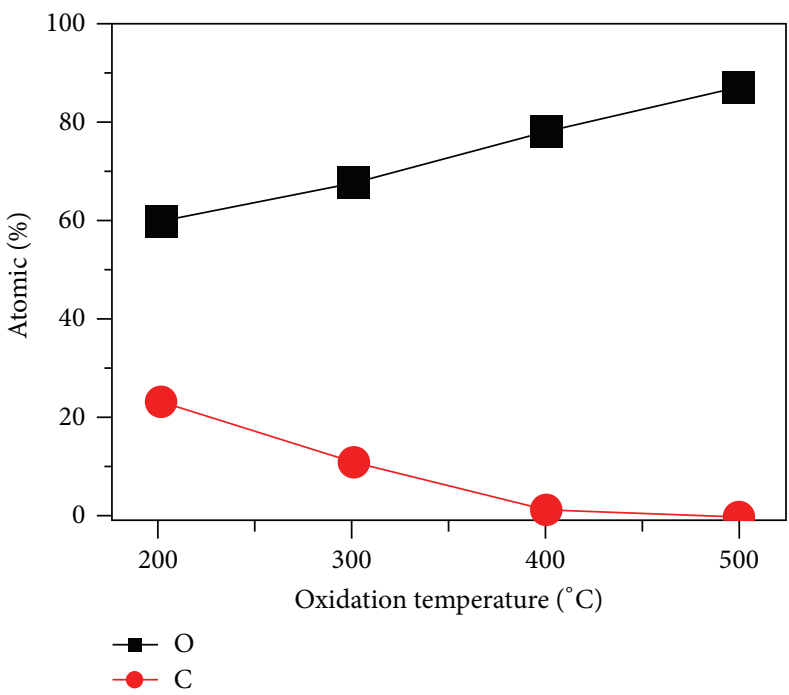

(a)

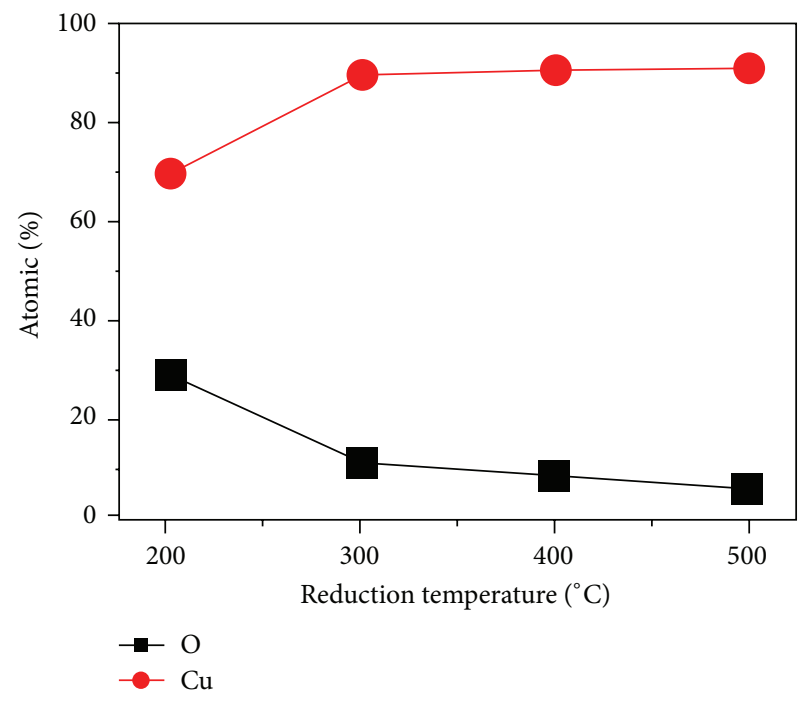

(b)

Figure 6: Atomic percent of (a) $\mathrm{C}$ and $\mathrm{O}$ after oxidation annealing at different temperatures and (b) $\mathrm{Cu}$ and $\mathrm{O}$ after reduction annealing at different temperatures for oxidation treated at $450^{\circ} \mathrm{C}$ for $\mathrm{Cu}$ nitrate trihydrate/PVB nanofibers.

detail, but it was clearly motivated by the decomposition temperature of PVB lower than PVA. Such a low processing temperature is a very useful requirement if variable substrates are to be introduced. Figure 5(c) clearly showed that the $\mathrm{Cu}$ nanofibers are now continuous on the substrate because of the lower reduction temperature employed.

3.3. Electrical and Light Transmitting Properties. The total amount of electrospinning for Cu nitrate trihydrate + PVB was varied from 0.010 to $0.040 \mathrm{~mL}$ to change the conduction and transparency of the TCFs. The morphologies of the $\mathrm{Cu}$ nanofibers fabricated according to the developed conditions $\left(450^{\circ} \mathrm{C}\right.$ oxidation and $300^{\circ} \mathrm{C}$ reduction) above are shown in Figure 7. Since $\mathrm{Cu}$ nanofibers running on the substrate are not transparent, the open spaces between the fibers determine the transmittance.

The light transparency and electrical conductivity for electrospinning with PVA and PVB mixtures are also compared in Table 1 for different total amount of electrospinning. The light transmission was not significantly different between PVA and PVB mixtures at each amount of electrospinning because total amounts of $\mathrm{Cu}$ covering the substrate are similar. However, the electrical resistance of the TCF made from the PVB mixture revealed a 10 -fold lower value than from the PVA mixture. The latter result is simply because of the discontinuity of the nanofibers on the substrate caused by the high reduction temperature used in the PVA mixture case.

The light transmittance of the as-electrospun solution, $\mathrm{CuO}$ nanofibers, and $\mathrm{Cu}$ nanofibers measured at various wavelengths was summarized in Figure 8 for $0.04 \mathrm{~mL}$ electrospinning. The light transmittance at the wavelength of $550 \mathrm{~nm}$ was $57 \%, 75 \%$, and $92 \%$ for the $\mathrm{Cu}$ nitrate trihydrate $+\mathrm{PVB}, \mathrm{CuO}$ nanofibers, and $\mathrm{Cu}$ nanofibers, respectively. The enhancement of the transmittance was thus caused by the
TABLE 1: Optical and electrical properties of the $\mathrm{Cu}$ nanofibers fabricated with different amounts of $\mathrm{Cu}$ source.

\begin{tabular}{lcc}
\hline Amount of Cu source & $\begin{array}{c}\text { Cu nanofiber } \\
\text { from PVA }+\mathrm{Cu} \\
\text { acetate }\end{array}$ & $\begin{array}{c}\text { Cu nanofiber } \\
\text { from PVB }+\mathrm{Cu} \\
\text { nitrate } \\
\text { trihydrate }\end{array}$ \\
\hline $0.010 \mathrm{~mL}$ & 91.7 \\
Transmittance (\%) & 91.4 & 284.6 \\
Resistance $(\Omega)$ & 4502.2 & \\
$0.025 \mathrm{~mL}$ & & 76.1 \\
Transmittance $(\%)$ & 80.2 & 94.3 \\
Resistance $(\Omega)$ & 840.7 & \\
$0.040 \mathrm{~mL}$ & & 59.2 \\
Transmittance $(\%)$ & 58.7 & 83.5 \\
Resistance $(\Omega)$ & 580.4 & \\
\hline
\end{tabular}

removal of polymer and oxygen from the fibers. The electrospun $\mathrm{Cu}$ nanofiber network as a transparent conductive film device was not yet optimized to show a comparable performance with other $\mathrm{Cu}$ nanowire films [18].

\section{Conclusions}

Electrospinning method to fabricate copper nanofibers spread on a substrate as transparent conductive films was studied. The processing steps are electrospinning of $\mathrm{Cu}$ solutions $(\mathrm{Cu}$ source materials + liquefaction polymer solutions) to form nanofibers, annealing in air ambient to remove polymer material and oxidize $\mathrm{Cu}$, and annealing in hydrogen ambient to change copper oxide nanofibers to copper nanofibers. Two kinds of diluent and liquefaction solutions of PVA and PVB were tested. PVA showed a 


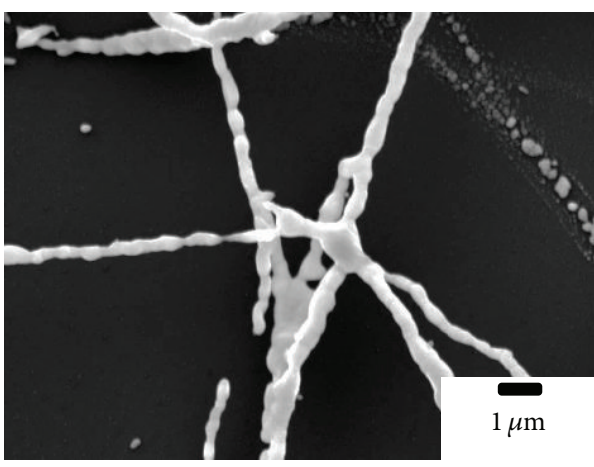

(a)

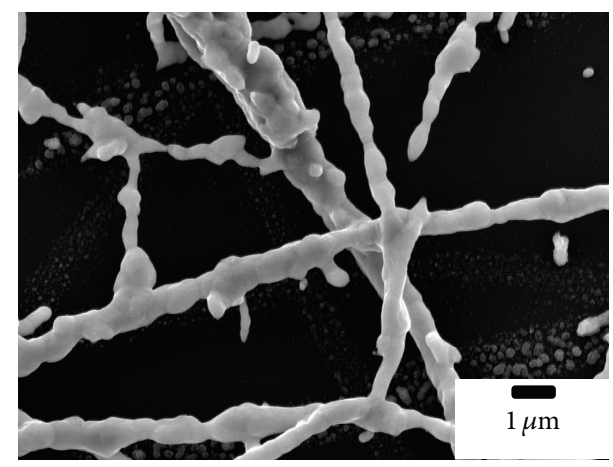

(b)

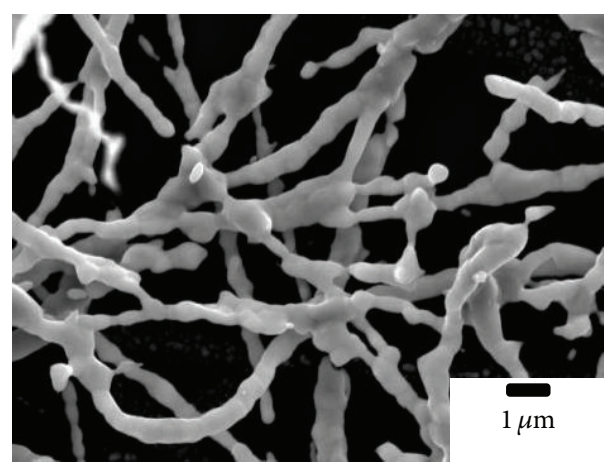

(c)

FIGURE 7: SEM images of Cu nanofibers formed by electrospinning of different amounts of the solution: (a) $0.010 \mathrm{~mL}$, (b) $0.025 \mathrm{~mL}$, and (c) $0.040 \mathrm{~mL}$.

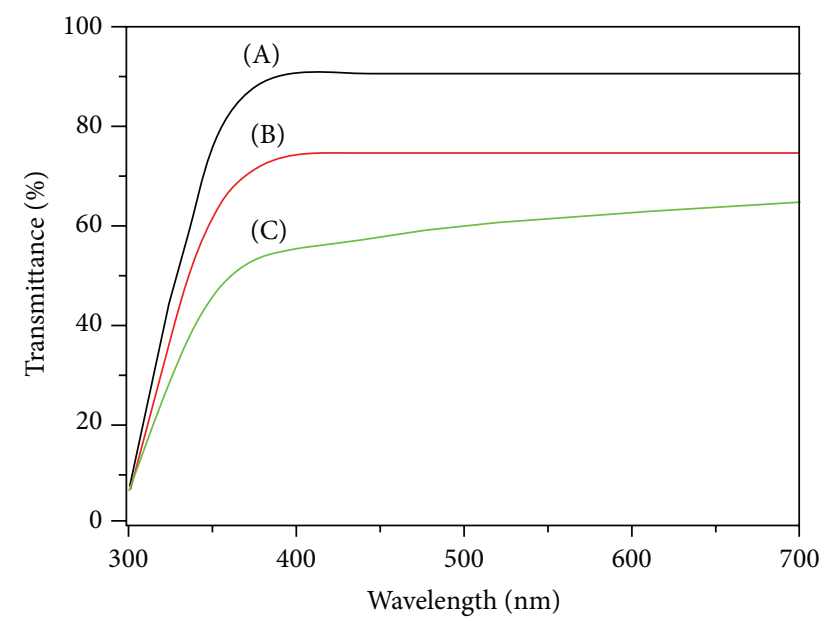

(A) Cu nanofiber

(B) $\mathrm{CuO}$ nanofiber

(C) PVB nanofiber

FIGURE 8: Transmittance of nanofiber networks of $\mathrm{Cu}$ nitrate trihydrate/PVB, $\mathrm{CuO}$, and $\mathrm{Cu}$ (the glass transmittance subtracted).

reaction with $\mathrm{Cu}$ acetate with mixing. This led to a high annealing temperature of $500^{\circ} \mathrm{C}$ for removal of PVA from the mixture. The high temperature oxidation possibly led to a high crystallinity $\mathrm{CuO}$, which in turn increased the reduction temperature required. It was $500^{\circ} \mathrm{C}$ in hydrogen ambient for $\mathrm{Cu}$ nanofiber network formation. The high reduction temperature was the main reason for the $\mathrm{Cu}$ nanofibers melting and consequent disconnection. In the meantime, $\mathrm{Cu}$ nitrate trihydrate mixing with $\mathrm{PVB}$ required lower oxidation and reduction temperatures of $450^{\circ} \mathrm{C}$ and $300^{\circ} \mathrm{C}$, respectively. The fabricated $\mathrm{Cu}$ nanofiber network led to a percolation condition, and a relatively simple economic procedure was developed. However, the heat treatment temperatures need to be further lowered for application to flexible polymer substrates.

\section{Conflict of Interests}

The authors declare that there is no conflict of interests regarding the publication of this paper.

\section{Acknowledgments}

This work was supported by the National Research Laboratory (NRF-2015R1A2A1A01006192) and the Basic Research Laboratory (no. NRF-2013R1A4A1069528) programs of the National Research Foundation of Korea.

\section{References}

[1] K. L. Chopra, S. Major, and D. K. Pandya, "Transparent conductors-a status review," Thin Solid Films, vol. 102, no. 1, pp. $1-46,1983$. 
[2] D. R. Cairns, R. P. Witte II, D. K. Sparacin et al., "Straindependent electrical resistance of tin-doped indium oxide on polymer substrates," Applied Physics Letters, vol. 76, no. 11, article 1425, 2000.

[3] Y. Leterrier, L. Médico, F. Demarco et al., "Mechanical integrity of transparent conductive oxide films for flexible polymer-based displays," Thin Solid Films, vol. 460, no. 1-2, pp. 156-166, 2004.

[4] J. L. Blackburn, T. M. Barnes, M. C. Beard et al., "Transparent conductive single-walled carbon nanotube networks with precisely tunable ratios of semiconducting and metallic nanotubes," ACS Nano, vol. 2, no. 6, pp. 1266-1274, 2008.

[5] Z. C. Wu, Z. H. Chen, X. Du et al., "Transparent, conductive carbon nanotube films," Science, vol. 305, no. 5688, pp. 12731276, 2004.

[6] E. M. Doherty, S. De, P. E. Lyons et al., “The spatial uniformity and electromechanical stability of transparent, conductive films of single walled nanotubes," Carbon, vol. 47, no. 10, pp. 24662473, 2009.

[7] H. Jung, J. S. Yu, H. P. Lee, J. M. Kim, J. Y. Park, and D. Kim, "A scalable fabrication of highly transparent and conductive thin films using fluorosurfactant-assisted single-walled carbon nanotube dispersions," Carbon, vol. 52, pp. 259-266, 2013.

[8] H. A. Becerril, J. Mao, Z. Liu, R. M. Stoltenberg, Z. Bao, and Y. Chen, "Evaluation of solution-processed reduced graphene oxide films as transparent conductors," ACS Nano, vol. 2, no. 3, pp. 463-470, 2008.

[9] J.-S. Yu, G. H. Jung, J. Jo et al., "Transparent conductive film with printable embedded patterns for organic solar cells," Solar Energy Materials and Solar Cells, vol. 109, pp. 142-147, 2013.

[10] K. S. Kim, Y. Zhao, H. Jang et al., "Large-scale pattern growth of graphene films for stretchable transparent electrodes," Nature, vol. 457, no. 7230, pp. 706-710, 2009.

[11] F. C. Krebs, "All solution roll-to-roll processed polymer solar cells free from indium-tin-oxide and vacuum coating steps," Organic Electronics, vol. 10, no. 5, pp. 761-768, 2009.

[12] Y. Galagan, J.-E. J. M. Rubingh, R. Andriessen et al., "ITO-free flexible organic solar cells with printed current collecting grids," Solar Energy Materials and Solar Cells, vol. 95, no. 5, pp. 13391343, 2011.

[13] S. De, T. M. Higgins, P. E. Lyons et al., "Silver nanowire networks as flexible, transparent, conducting films: extremely high DC to optical conductivity ratios," ACS Nano, vol. 3, no. 7, pp. 17671774, 2009.

[14] L. Hu, H. S. Kim, J.-Y. Lee, P. Peumans, and Y. Cui, "Scalable coating and properties of transparent, flexible, silver nanowire electrodes," ACS Nano, vol. 4, no. 5, pp. 2955-2963, 2010.

[15] J. Lee, P. Lee, H. Lee et al., "Very long Ag nanowire synthesis and its application in a highly transparent, conductive and flexible metal electrode touch panel," Nanoscale, vol. 4, no. 20, pp. 64086414, 2012.

[16] W. Gaynor, G. F. Burkhard, M. D. McGehee, and P. Peumans, "Smooth nanowire/polymer composite transparent electrodes," Advanced Materials, vol. 23, no. 26, pp. 2905-2910, 2011.

[17] D. Lee, H. Lee, Y. Ahn, Y. Jeong, D.-Y. Lee, and Y. Lee, "Highly stable and flexible silver nanowire-graphene hybrid transparent conducting electrodes for emerging optoelectronic devices," Nanoscale, vol. 5, no. 17, pp. 7750-7755, 2013.

[18] A. R. Rathmell and B. J. Wiley, "The synthesis and coating of long, thin copper nanowires to make flexible, transparent conducting films on plastic substrates," Advanced Materials, vol. 23, no. 41, pp. 4798-4803, 2011.
[19] H. Guo, N. Lin, Y. Chen et al., "Copper nanowires as fully transparent conductive electrodes," Scientific Reports, vol. 3, article 2323, 2013.

[20] H. Xiang, Y. Long, X. Yu, X. Zhang, N. Zhao, and J. Xu, "A novel and facile method to prepare porous hollow $\mathrm{CuO}$ and $\mathrm{Cu}$ nanofibers based on electrospinning," CrystEngComm, vol. 13, no. 15, pp. 4856-4860, 2011.

[21] P.-C. Hsu, H. Wu, T. J. Carney et al., "Passivation coating on electrospun copper nanofibers for stable transparent electrodes," ACS Nano, vol. 6, no. 6, pp. 5150-5156, 2012.

[22] S. Sharma, R. Rani, R. Rai, and T. S. Natarajan, "Synthesis and characterization of $\mathrm{CuO}$ electrospum nanofiber using poly(vinyl acetate) $/ \mathrm{Cu}\left(\mathrm{CH}_{3} \mathrm{COO}\right)_{2}$ annealing method," Advanced Materials Letters, vol. 4, no. 10, pp. 749-753, 2013.

[23] H. Wu, L. Hu, M. W. Rowell et al., "Electrospun metal nanofiber webs as high-performance transparent electrode," Nano Letters, vol. 10, no. 10, pp. 4242-4248, 2010.

[24] Z. H. Mbhele, M. G. Salemane, C. G. C. E. van Sittert, J. M. Nedeljković, V. Djoković, and A. S. Luyt, "Fabrication and characterization of silver-polyvinyl alcohol nanocomposites," Chemistry of Materials, vol. 15, no. 26, pp. 5019-5024, 2003.

[25] C. Shao, H. Guan, Y. Liu, and R. Mu, "MgO nanofibres via an electrospinning technique," Journal of Materials Science, vol. 41, no. 12, pp. 3821-3824, 2006.

[26] C. Pan, R. Ding, Y. Hu, and G. Yang, "Electrospinning fabrication of rime-like $\mathrm{NiO}$ nanowires/nanofibers hierarchical architectures and their photocatalytic properties," Physica E: Low-Dimensional Systems and Nanostructures, vol. 54, pp. 138143, 2013.

[27] H. Wu and W. Pan, "Preparation of zinc oxide nanofibers by electrospinning," Journal of the American Ceramic Society, vol. 89, no. 2, pp. 699-701, 2006.

[28] H. Wang, X. Lu, Y. Zhao, and C. Wang, "Preparation and characterization of $\mathrm{ZnS}$ :Cu/PVA composite nanofibers via electrospinning," Materials Letters, vol. 60, no. 20, pp. 2480-2484, 2006.

[29] R. Nirmala, D. Kalpana, J. W. Jeong et al., "Multifunctional baicalein blended poly(vinyl alcohol) composite nanofibers via electrospinning," Colloids and Surfaces A: Physicochemical and Engineering Aspects, vol. 384, no. 1-3, pp. 605-611, 2011.

[30] R. V. Kumar, O. Palchik, Y. Koltypin, Y. Diamant, and A. Gedanken, "Sonochemical synthesis and characterization of Ag2S/PVA and CuS/PVA nanocomposite," Ultrasonics Sonochemistry, vol. 9, no. 2, pp. 65-70, 2002.

[31] H. Wang, P. Fang, Z. Chen, and S. Wang, "Synthesis and characterization of CdS/PVA nanocomposite films," Applied Surface Science, vol. 253, no. 20, pp. 8495-8499, 2007.

[32] Q. Zhang, K. Zhang, D. Xu et al., "CuO nanostructures: synthesis, characterization, growth mechanisms, fundamental properties, and applications," Progress in Materials Science, vol. 60, pp. 208-337, 2014.

[33] A. K. Dhaliwal and J. N. Hay, "The characterization of polyvinyl butyral by thermal analysis," Thermochimica Acta, vol. 391, no. 1-2, pp. 245-255, 2002.

[34] J. J. Seo, S. T. Kuk, and K. Kim, “Thermal decomposition of PVB (polyvinyl butyral) binder in the matrix and electrolyte of molten carbonate fuel cells," Journal of Power Sources, vol. 69, no. 1-2, pp. 61-68, 1997.

[35] L.-J. Chen, J.-D. Liao, S.-J. Lin, Y.-J. Chuang, and Y.-S. Fu, "Synthesis and characterization of PVB/silica nanofibers by electrospinning process," Polymer, vol. 50, no. 15, pp. 3516-3521, 2009. 

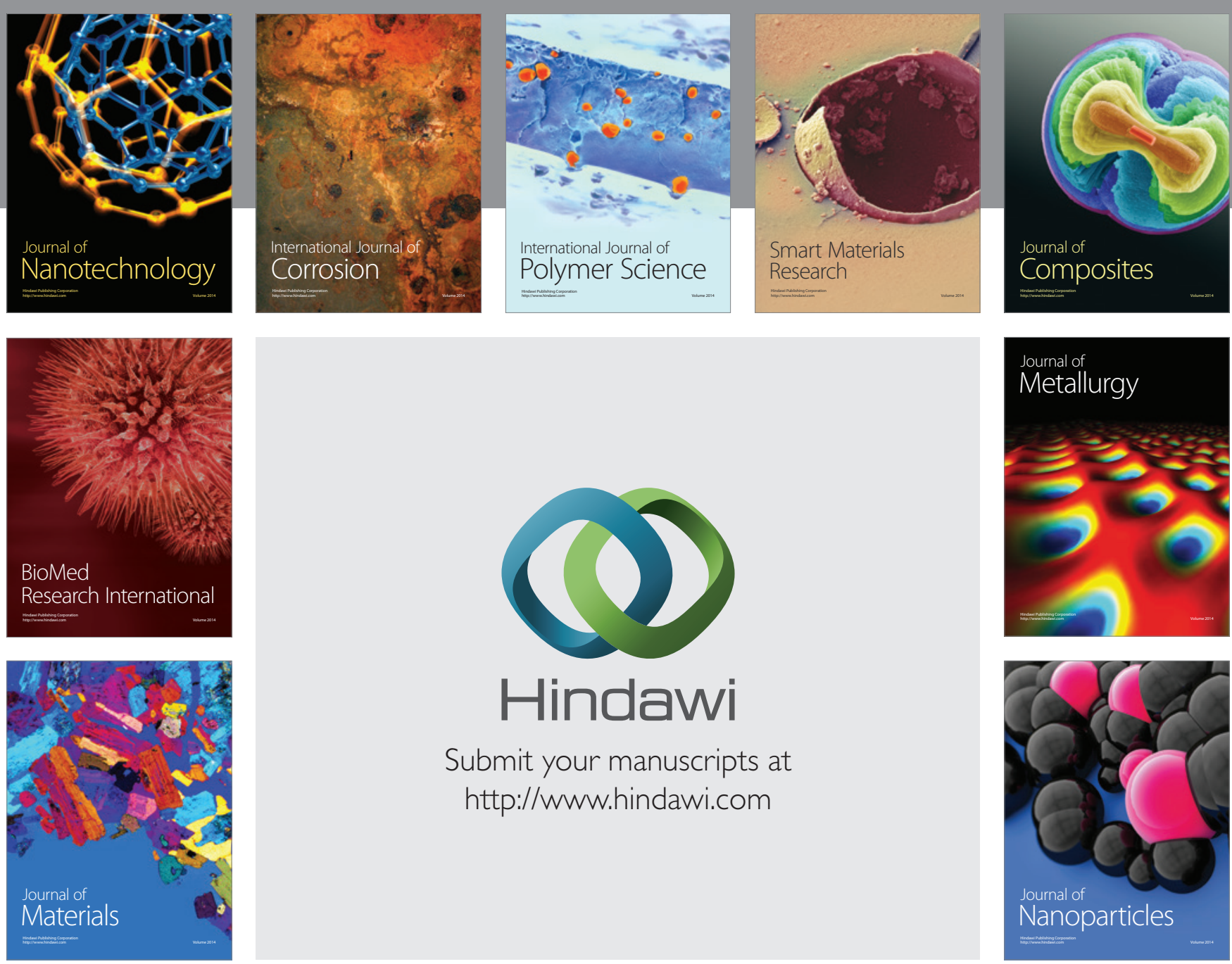

Submit your manuscripts at http://www.hindawi.com
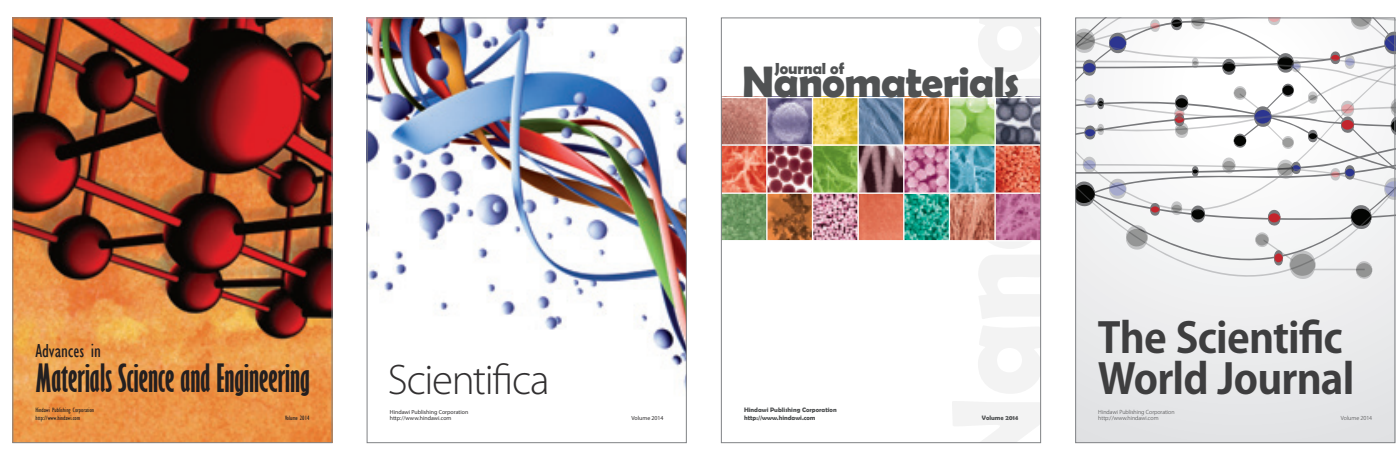

\section{The Scientific World Journal}
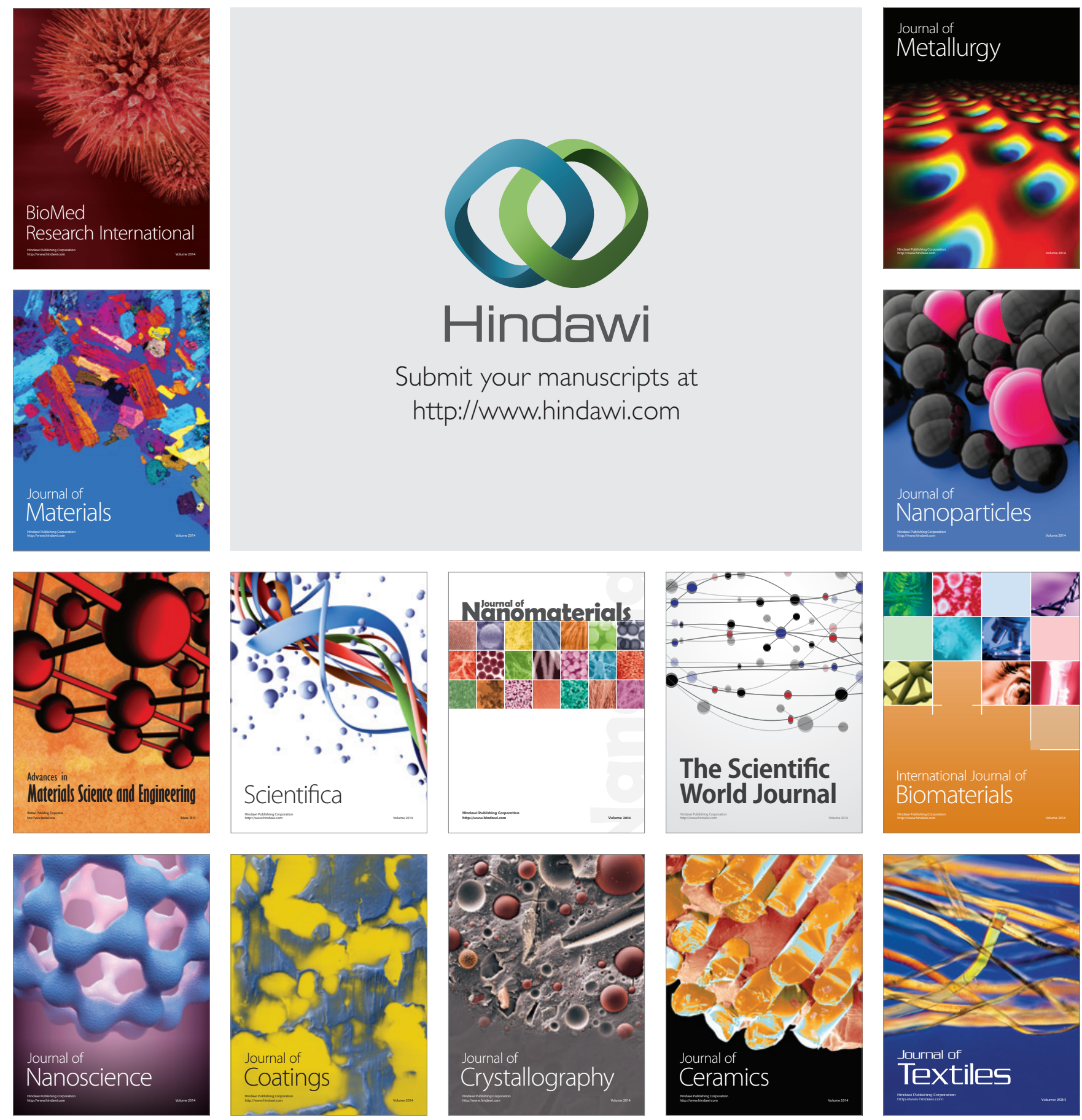